\title{
Neutral zone or conventional mandibular complete dentures: a randomised crossover trial comparing oral health-related quality of life
}

\author{
G. A. V. M. Geerts
}

\section{Summary}

There is widespread consensus that the neutral zone (NZ) concept contributes to improved stability for mandibular complete dentures (CDs). However, little is known about its impact on oral health-related quality of life (OHRQoL) of edentulous patients compared to conventionally (CV) manufactured dentures. In this prospective crossover trial, performed at the Oral Health Centre of the University of the Western Cape, CV and NZ mandibular dentures were made for each patient. Scores from the 20-item oral health impact profile (OHIP-20) for both types of dentures were compared with pre-treatment scores using paired t-tests. Treatment effect size (ES) was established. Associations of OHIP-20 scores and several patient variables (age, gender, period of edentulousness, quality of the denturebearing tissue, denture dimensions, preference) were performed using the generalised linear model. Significance was set at $\mathrm{P}=0.05$. Records of thirty-five participants were included in the study (mean age of 62.3 years, range 47-85 years). There were highly significant differences between pre-treatment and both posttreatment OHIP-20 scores with $\mathrm{t}=6.470$ for $\mathrm{CV}$ and $\mathrm{t}=6713$ for NZ. Treatment ES was large for both types of dentures $(>0.8)$. Difference of ES between NZ and CV dentures was small (ES < 0.2). None of the patient variables showed significant associations with OHIP-20 scores of the two types of dentures, except for preference and NZ OHIP-20 scores. For this group of patients, both treatment methods improved OHRQoL significantly and patientrelated factors did not influence impact on OHRQoL differently for both interventions.

\section{Introduction}

Treatment with complete dentures (CDs) remains the only therapeutic option for edentulous people who do not have access to implant treatment. Poor denture stability and retention may cause chronic functional limitations and discomfort (1). Therefore, improved CD stability and retention would impact positively on treatment outcomes. It is generally accepted that CD stability is assisted by means of muscular action when CDs are made to conform to the neutral zone (NZ). The NZ is defined as a specific zone within the potential denture space where oral function will not unseat the denture; in fact, tooth position and flange contour are considered at least as important for denture stability as any other factor 
(2). There is consensus among experts that the NZ should be respected when constructing CDs (3), in spite of paucity of high-level evidence supported by controlled clinical studies. From the few published trials, it appears that NZ dentures have a clinical benefit over conventional (CV) dentures (4-7). Except for quality of supporting tissues, none of these trials comparing conventional (CV) and NZ dentures addressed how patient variables impacted differently on oral health-related quality of life (OHRQoL) comparing the two interventions.

The ultimate aim for rehabilitating edentulousness is an improvement of OHRQoL of the patient. Therefore, assessment of treatment outcomes by means of patientbased outcomes (PBOs) is important. This becomes all the more obvious when it is understood that: (i) there is a poor correlation between clinical variables and patient satisfaction (8), (ii) the quality of the denturebearing tissue is a poor predictor for patient satisfaction (9), and (iii) there is a poor agreement between patients and prosthodontist when rating dentures (9). There has been a growth in instruments to measure OHRQoL. The 20-item oral health impact profile (OHIP-20), developed from the longer OHIP-49 (10), is often used to determine impact on OHRQoL following rehabilitation of edentulousness. It covers seven domains: functional limitation, physical pain, psychological discomfort, physical disability, psychological disability, social disability and handicap. For the edentulous scenario, it appeared to measure change as effectively as the 49-item OHIP (11).

Could NZ mandibular dentures be considered better quality-dentures than CV mandibular dentures and have a more positive impact on treatment outcome? Do patient variables impact on PBOs? To answer these questions, a prospective, randomised crossover trial was done comparing impact on OHRQoL when edentulous patients are treated with NZ and CV dentures. In addition, associations were made between OHRQoL and several patient variables: age, gender, period of edentulousness, quality of the denture-bearing tissue, differences in width between the two types of dentures and preference. The first nullhypothesis was that the NZ denture is not superior in terms of OHRQoL. The second nullhypothesis was that patient variables are not associated with either of the dentures' impact on OHRQoL.

\section{Methods}

The trial proposal was approved by the Research Committee of the University of the Western Cape (registration number 11/1/49). The trial was done at the Tygerberg Oral Health Centre, being a training and service-rendering site for the Faculty of Dentistry of the University. All clinical, technical and research work was performed by the same individual. Between 2011 and 2014, all patients requesting new CDs at the Oral Health Centre were screened. Those conforming to the inclusion and exclusion criteria, understanding and signing written informed consent were selected. Patient inclusion was as follows: edentulousness; between 40 and 85 years old; denture experience (patient should not be a firsttime complete denture wearer); able to read, understand and respond to the OHIP-20 instrument (in English); ability to attend 9-10 visits. Exclusion criteria were as follows: temporomandibular disorder 
symptoms; oral pathology requiring intervention preventing immediate start of fabrication of new complete dentures; parafunction; severe xerostomia; orofacial motor disorders; severe oral manifestations of systemic disease; psychological or psychiatric conditions that could influence response to treatment; patients wanting dental implants. No important changes to the methods were made after commencement of the trial.

Two sets of CDs were constructed for each patient. The maxillary dentures were made to be identical for both sets. Standard clinical prosthetic procedures for fabricating dentures were followed. Sequence of visits and materials used are shown in Table 1.

Table 1. Sequence of visits and materials used

\begin{tabular}{|c|c|}
\hline Visit & Procedures and materials \\
\hline 1 & $\begin{array}{l}\text { Primary impressions with edentulous } \\
\text { stock trays (Eezitray, Wright Health Group, } \\
\text { Dundee, Scotland). Irreversible hydrocolloid impression } \\
\text { material (Blue Print, Dentsply De Trey GmbH, Konstanz, } \\
\text { Germany) }\end{array}$ \\
\hline 2 & $\begin{array}{l}\text { Definitive impressions with custom-made trays (Megatray, } \\
\text { Megadenta, Radeberg, Germany), border moulding with } \\
\text { modelling plastic impression compound (Greenstick, } \\
\text { KerrHawe SA Bioggio, Switzerland) and zinc oxide } \\
\text { eugenol impression paste (SS White, SS White, } \\
\text { Lakewood, USA) }\end{array}$ \\
\hline 3 & $\begin{array}{l}\text { Jaw registration with wax record rims (Denture } \\
\text { modelling wax sheets, Kemdent, Wiltshire, UK) }\end{array}$ \\
\hline 4 & $\begin{array}{l}\text { Try-in of the CV wax trial denture. Neutral zone } \\
\text { impression using modelling plastic impression } \\
\text { compound rim on resin base (Rapid-repair, Dentsply, } \\
\text { Surrey, UK) according to Cagna et al. (12) }\end{array}$ \\
\hline 5 & $\begin{array}{l}\text { Try-in of NZ wax trial dentures. Verification impressions } \\
\text { of facial and lingual surfaces of mandibular dentures } \\
\text { using zinc oxide eugenol impression paste according to } \\
\text { Cagna et al. (12) }\end{array}$ \\
\hline 6 & $\begin{array}{l}\text { Clinical remount and delivery of first set of dentures. } \\
\text { Recalls }\end{array}$ \\
\hline 7 & $\begin{array}{l}\text { Clinical remount and delivery of second set of dentures. } \\
\text { Recalls }\end{array}$ \\
\hline
\end{tabular}

CV, conventional; NZ, neutral zone.

For the $\mathrm{CV}$ mandibular denture, the posterior mandibular teeth were arranged according to a modified Pound triangle; For the NZ mandibular denture, the technique described by Cagna et al. was followed (12). A lingualised, balanced occlusion without compensating curves was used for both denture sets. Each set of CDs was worn for at least 8 weeks after the last recall visit. Upon delivery of the second set of CDs, the first set was withheld from the patient. Patients were blinded to the type of dentures worn and were not informed on the nature of the difference between the two sets of CDs.

Age, sex and denture-wearing history were recorded for each patient. The prosthodontic diagnostic index (PDI) was determined for each patient (13). Twenty-item oral health impact 
profile questionnaires (OHIP-20) were completed before treatment and for each new set of dentures after wearing it for at least 8 weeks after the last adjustment visit. At the end of the trial, preference had to be expressed (CV, NZ or none). Widths of denture arches were measured at the levels of molar, pre-molar and canine positions for both $\mathrm{CV}$ and $\mathrm{NZ}$ mandibular dentures. The overall mean of the difference in these widths was calculated.

A power analysis was done after a pilot group of four patients was completed using a one sample $\mathrm{t}$-test. The aim of the test was to reject the hypothesis that there was no difference between groups if the mean fell outside the interval $(-\mathrm{z \sigma} / \sqrt{ } \mathrm{n},+\mathrm{z \sigma} / \sqrt{ } \mathrm{n})$, where $\mathrm{z}$ was chosen according to the desired significance level, typically approximately 1.96 or $1.645, \mathrm{r}$ was the standard deviation (std) of the differences, $n$ was the sample size. For the four patients, an estimate of the std was 10.3. The std for pre-treatment minus NZ denture score was 34.5; for the pre-treatment minus $\mathrm{CV}$ denture score, the std was 41.o. If the true mean difference (CV minus NZ denture scores) is $\mathrm{D}>0$, then for a moderately large $\mathrm{n}$ the power of a one-sided $\mathrm{t}-$ test at level 0.05 is $\operatorname{Pr}[\mathrm{D}>1.645 \sigma / \sqrt{ } \mathrm{nIE}[\mathrm{D}=\Delta]=1 \Phi[1.645-\Delta \sqrt{ } \mathrm{n} / \sigma]$ where $\Phi$ is the standard normal c.d.f. Inverting the above formula, if $\sigma=10, \Delta=5$ and power $=0.9$, the required sample size was 34. Patients were randomly assigned to receive 1 of the 2 treatments first, by means of random draw from a container holding 40 tickets coded with equal numbers of CV and NZ. Data from patients from the pilot study were added to the data of the final trial. To determine a possible carry-over and treatment effect between the two treatment sequence groups, a two sample t-test was done.

Treatment effect size (ES) was calculated as the difference of mean pre- and post-treatment OHIP-2O scores divided by the std of the mean pre-treatment score (14). Comparison of pretreatment OHIP-20 scores with post-treatment scores was done by means of paired t-tests. Association between CV and NZ OHIP-20 scores were analysed using Spearman rank correlation. Associations of OHIP-20 scores with patient variables were made by means of regression analysis using generalised linear models (GLMs). These variables were age of the patient at the time of his/her first visit; gender; period of edentulousness calculated between the time of the loss of the last remaining teeth and the first visit of this trial; quality of the denture-bearing tissue by means of the PDI; difference in arch widths between CV and NZ dentures and CV or NZ preference. For all statistical tests, level of significance was determined at $\mathrm{P}=0.05$. No adjustments were made for multiplicity.

\section{Results}

Patient allocation and retention are shown in the flow diagram (Fig. 1). Two participants did not return for their second denture (1 NZ and $1 \mathrm{CV}$ ), therefore were not included in the analysis. 


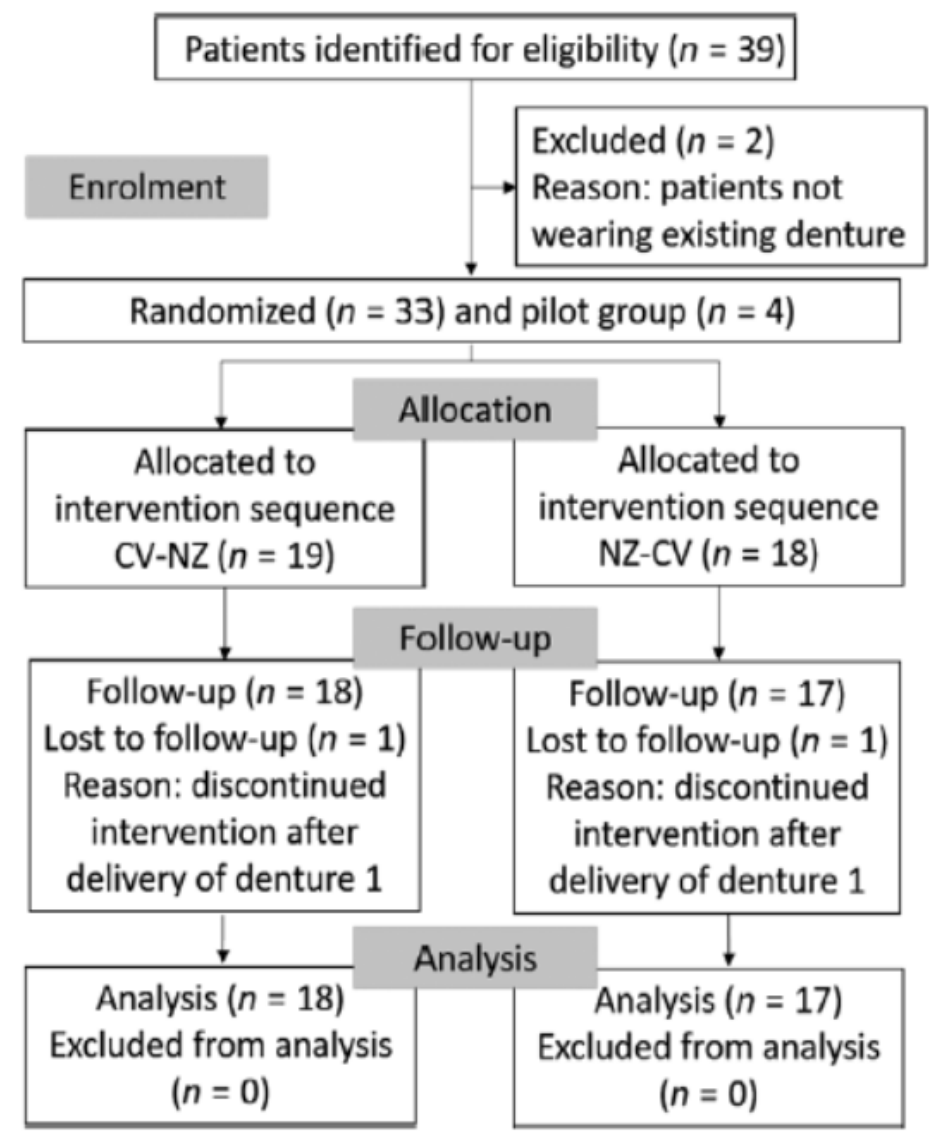

Fig. 1. Flow diagram for patient allocation and retention.

Thirty-five participants were included in the analysis. Mean age of these participants was 62.3 years (range $47-85$ years, std 9.2). Fourteen participants were male. Mean period of edentulousness was 30_9 years (range 1-60 years, std 14.5). Seventy-four per cent of participants were in class III and IV of the PDI (most challenging).

No significant carry-over $(t=1.000 ; P=0.324)$ or treatment effect $(t=1.533 ; P=0.134)$ was found between the two sequence groups.

Table 2 shows pre-treatment and both post-treatment OHIP-20 scores per domain. The difference in mean OHIP-20 scores for pre-treatment minus CV was 27.61; for pre-treatment minus NZ, it was 27.93; and for CV minus NZ, it was 0.32. Paired t-test demonstrated highly significant differences between pre-treatment and both post-treatment OHIP-20 scores with $t=6.470$ for $\mathrm{CV}(P=$ and $t=6.713$ for NZ). A statistical significant positive correlation was found between CV and NZ OHIP-20 scores before adjusting for the pre-treatment OHIP scores (Spearman rank correlation coefficient $\mathrm{r}=0.733, \mathrm{P}<0.001$ ) as well as after adjustment $(r=0.8752, P<0.001)$. 
A GLM-relating OHIP-20 scores with age showed a weak-negative relationship for CV dentures (constant: 17_6; coefficient_0_047; $\mathrm{P}=0$ 0_877) and weak-positive relationship for NZ dentures (constant: 10_5; coefficient $0 \_048 ; \mathrm{P}=0 \_891$ ). None of the relationships were statistically significant.

Mean post-treatment OHIP-20 scores for male participants was 13_4 (std) and 15_9 (std 21_0) for the CV and NZ dentures respectively. The mean posttreatment OHIP-20 score of female participants was 15.5 (std 13.2) and 11.9 (std 17.8) for the CV and NZ dentures, respectively. A GLM-relating OHIP-2O scores with gender showed that none of the relationships were statistically significant ( $P=0.705$ for $\mathrm{CV}$ and $P=0.534$ for NZ dentures).

A GLM-relating period of edentulousness with difference in OHIP-20 scores of the two types of dentures showed that none of the relationships were statistically significant (Constant: 0.179; coefficient 0.032; $P=0.835$ ).

Table 3 shows the results of the GLM, relating PDI with difference in OHIP-20 scores. None of the relationships were statistically significant $(P=0.280, P=0.245, P=0.495$ and $P=$ 0.145 for PDI's of 1, 2, 3 and 4, respectively).

Mean distances between posterior teeth of NZ dentures were always larger than for CV dentures. Mean differences in widths in $\mathrm{mm}$ between CV and NZ dentures were 4_42, 5_25, 5.66, 4.70 and 3.10 for third, second, first molar, second and first pre-molar regions, respectively. Using the GLM, relating overall mean of the difference in widths of dentures with the differences in OHIP-20 scores showed that none of the relationships were statistically significant (constant 4.382; coefficient 0.008; $P=0.839$ ).

Table 4 shows the results of the GLM, relating OHIP-20 with denture preference. There was no close association of OHIP-20 with preference, except for NZ preference, with a coefficient of 19_904 which was statistically significant $(\mathrm{P}=0.000)$.

Treatment ES for the CV denture was 1.22; for the NZ denture, it was 1.24. Full results of treatment ES are given in table 5 . 
Table 2. Pre-treatment and both post-treatment OHIP-20 scores per domain

\begin{tabular}{lcrr}
\hline Mean OHIP-20 scores per domain $(n=35)$ & & \\
\hline Domain & Pre-treatment & CV & NZ \\
\hline Functional limitation & 8.3 & 3.9 & 3.9 \\
Physical pain & 8.6 & 4.3 & 3.5 \\
Psychological discomfort & 4.9 & 1.3 & 1.1 \\
Physical disability & 8.2 & 2.8 & 2.8 \\
Psychological disability & 4.7 & 1.1 & 1.0 \\
Social disability & 5.9 & 0.8 & 1.5 \\
Handicap & 1.7 & 0.3 & 0.4 \\
Mean sum & 42.1 & 14.5 & 14.2 \\
Range & 4.8 & 0.8 & 0.8 \\
Std & 22.6 & 16.6 & 19.0 \\
\hline
\end{tabular}

Table 3. Results of the GLM, relating PDI with difference in OHIP-20 scores

\begin{tabular}{|c|c|c|c|c|c|c|}
\hline \multirow{2}{*}{$\begin{array}{l}\text { CV minus } \\
\text { NZ } \\
\text { OHIP-20 }\end{array}$} & \multicolumn{6}{|l|}{ GLM } \\
\hline & Coef. & SE & $\mathrm{z}$ & $P>|z|$ & $\begin{array}{l}95 \% \text { Conf } \\
\text { interval }\end{array}$ & fidence \\
\hline PDI 2 & 9.750 & 8.385 & $1 \cdot 16$ & 0.245 & $-6 \cdot 684$ & $26 \cdot 184$ \\
\hline PDI 3 & $4 \cdot 878$ & $7 \cdot 147$ & 0.68 & 0.495 & $-9 \cdot 129$ & 18.886 \\
\hline PDI 4 & $10 \cdot 404$ & $7 \cdot 147$ & 1.46 & 0.145 & -3.604 & 24.412 \\
\hline Constant & $-6 \cdot 750$ & 6.250 & -1.08 & 0.280 & -18.999 & 5.499 \\
\hline
\end{tabular}

Table 4. Results of the GLM, relating OHIP-20 with denture preference

\begin{tabular}{|c|c|c|c|c|c|c|c|c|c|}
\hline \multirow[b]{2}{*}{ Preference } & \multirow[b]{2}{*}{$N$} & \multirow[b]{2}{*}{ Mean } & \multirow[b]{2}{*}{ std } & \multicolumn{6}{|l|}{ GLM } \\
\hline & & & & Coef & SE & $\mathrm{z}$ & $P>|z|$ & $\begin{array}{l}95 \% \text { Con } \\
\text { interval }\end{array}$ & \\
\hline $\mathrm{CV}$ & 8 & -8.94 & 11.3 & & & & & & \\
\hline NZ & 13 & 10 & 11.04 & 19.904 & 4.590 & $4 \cdot 31$ & $0.000^{*}$ & $10 \cdot 809$ & 28.800 \\
\hline None & 14 & -3.45 & 9.4 & 5.485 & $4 \cdot 646$ & $1 \cdot 18$ & 0.238 & -3.621 & 14.592 \\
\hline Constant & & & & -8.938 & 3.707 & -2.41 & 0.016 & $-16 \cdot 202$ & -1.673 \\
\hline
\end{tabular}

GLM, generalised linear model; OHIP-20, 20 -item oral health impact profile; $n$, number of patients; std, standard deviation; CV, conventional denture; NZ, neutral zone denture; Coef, coefficient; SE, standard error.

*Significant. 
Table 5. Treatment effect size per domain

\begin{tabular}{llll}
\hline & \multicolumn{2}{l}{ ES } & \\
\cline { 2 - 4 } OHIP-20 domain & $\mathrm{CV}$ & $\mathrm{NZ}$ & $\mathrm{NZ}$ minus CV \\
\hline Functional limitation & 1.06 & 1.08 & 0.02 \\
Physical pain & 0.73 & 0.86 & 0.13 \\
Psychological discomfort & 1.08 & 1.12 & 0.04 \\
Physical disability & 0.97 & 0.97 & 0.01 \\
Psychological disability & 1.15 & 1.18 & 0.04 \\
Social disability & 0.74 & 0.74 & 0.00 \\
Handicap & 0.80 & 0.81 & 0.02 \\
Sum & 1.22 & 1.24 & 0.02 \\
\hline
\end{tabular}

ES, treatment effect size; OHIP-20, 20-item oral health impact profile; CV, conventional denture; NZ, neutral zone denture.

\section{Discussion}

For this group of patients, a statistically significant difference between pre-treatment and both post-treatment OHIP-20 scores was found. Therefore, both treatment methods improved OHRQoL of patients compared to their pre-treatment situation. In addition, in order to recognise clinically meaningful change, treatment ES was determined. The standardised ES is the most popular distribution-based approach and has been endorsed by the Cochrane Collaboration for meta-analysis (15). Using treatment ES statistics, the difference in pre- and post-treatment ES was large and hence was considered clinically meaningful (clinically meaningfulness of ES: $0 \_2=$ small; $0 \_6=$ moderate; $0 \_8=$ large) (14). There was a significant positive correlation between changes in OHRQoL for both types of dentures. Hence, the first null-hypothesis, that the NZ denture is superior to the CV denture, is rejected.

Most trials assessing OHRQOL and CD satisfaction found an improvement in impacts and ratings after treatment, even though improvement may be small and limited to some domains only $(1,16-25)$. The results of the current trial are in line with these studies, except that the improvements were considerable and for all the domains. In fact, treatment ES was 1.2 for both types of dentures. This is similar or even larger than treatment ES in studies reporting on implant overdentures, which are considered to be more efficient in reducing negative impact on OHRQoL than conventional CDs [ES = 1.09 (1); ES = 1.2 (23); and ES = 1.3 (26)]. In the current trial, for both interventions, all domain ES scores were between 0.73 and 1.18. Therefore, both interventions led to 'large' improvement in OHRQoL in all seven domains of the OHIP-2O instrument. 
Reasons for this large treatment ES may be multiple: all patients came to the clinic with a perceived treatment need. Hence, they were dissatisfied with their existing prostheses and had high pre-treatment impact scores. All patients received the treatment of their choice. Patients requesting implant treatment were excluded. It has been reported that preferred treatment choice could affect satisfaction ratings $(16,27)$. Satisfaction is relative and dependent on treatment acceptance (26). Patients consenting to become involved in 'research' and the provision of care within a school of dentistry by a senior member of staff as opposed to pre-graduate students could have meant that patients perceived the quality of care as superior. The overwhelming effect of these conditions may have dampened the difference in treatment effects between the two types of dentures.

There was a significant positive correlation between both post-treatment methods, indicative of no difference in impact on OHRQoL between the two types of dentures. No prospective controlled crossover trial was found reporting on changes in OHRQoL comparing NZ and ANA dentures using OHIP-20. Therefore, relating data from the current trial with existing published results were not possible.

Literature has been dealing with complex issues such as the role of gender, age, quality of supporting tissues, period of edentulousness, and how they impact on OHRQoL when treating edentulous patients, without reaching clear consensus. When comparing CV with NZ dentures, this study showed that none of the patient variables can be used to predict which of the two treatment interventions would benefit a particular patient more in terms of OHRQoL. Therefore, the second nullhypothesis is accepted, with exception of a significant positive relationship of preference for a NZ denture and positive impact on OHRQoL.

The limitations of the study were that all patients had denture-wearing experience. The trial was performed by a single operator and was not operatorblinded because the difference in $\mathrm{NZ}$ and CV was clinically noticeable. Extrapolation of results across the profession is to be done with caution.

\section{Conclusions}

Within the limitations of this study, it can be concluded that:

1 Oral health-related quality of life improved significantly when edentulous patients received new dentures made following both CV and NZ techniques.

2 Dentures made according to the NZ technique were not proven to produce statistically superior OHRQoL results.

3 Patient variables such as gender, age, period of edentulousness, PDI scores, difference in denture widths of $\mathrm{CV}$ and $\mathrm{NZ}$ denture and preference did not impact differently on the respective OHIP-20 scores for $\mathrm{CV}$ or NZ dentures.

4 The ES for both treatment interventions was large. The ES difference between the two interventions was very small. 


\section{Ethical approval}

The trial proposal was approved by the Research Committee of the University of the Western Cape (registration number 11/1/49).

\section{Funding}

The University of the Western Cape is acknowledged for providing funding for purchasing materials and acquiring statistical services for the trial.

\section{Conflict of interest}

The author has stated explicitly that there are no conflict of interests in connection with this article. 


\section{References}

1. Heydecke G, Locker D, Awad MA, Lund JP, Feine JS. Oral and general health-related quality of life with conventional and implant dentures. Community Dent Oral Epidemiol. 2003;31:161-168.

2. Beresin VE, Schiesser FJ. The neutral zone in complete dentures. J Prosthet Dent. 1976;36:356-367. Reprinted in 2006.

3. Owen CP. Guidelines for a minimum acceptable protocol for the construction of complete dentures. Int J Prosthodont. 2006;19:467-474.

4. Walsh JF, Walsh T. Muscle-formed complete mandibular dentures. J Prosthet Dent. 1976;35:254-258.

5. Barren€as L, €Odman P. Myodynamic and conventional construction of complete dentures: a comparative study of comfort and function. J Oral Rehabil. 1989;16:457-465.

6. Fahmy FM, Kharat DU. A study of the importance of the neutral zone in complete dentures. J Prosthet Dent. 1990;64:459-462.

7. Rehmann P, K€unkel AK, Weber D, Lotzmann U, W€ostmann B. Using a modified neutral zone technique to improve the stability of mandibular complete dentures: a prospective clinical study. Int J Prosthodont. 2016;29:570-572.

8. Van Waas MA. The influence of clinical variables on patient satisfaction with complete dentures. J Prosthet Dent. 1990;63:307-310.

9. Heydecke G, Klemetti E, Awad MA, Lund JP, Feine JS. Relationship between prosthodontic evaluation and patient ratings of mandibular conventional and implant prostheses. Int J Prosthodont. 2003;16:307-312.

10. Slade G, Spencer A. Development and evaluation of the oral health impact profile. Community Dent Health. 1994;11: 3-11.

11. Allen F, Locker D. A modified short version of the oral health impact profile for assessing health-related quality of life in edentulous adults. Int J Prosthodont. 2002;15:446450 .

12. Cagna DR, Massad JJ, Schiesser FJ. The neutral zone revisited: from historical concepts to modern application. J Prosthet Dent. 2009;101:405-412.

13. McGarry TJ, Nimmo A, Skiba JF, Ahlstrom RH, Smith CR, Koumjian JH. Classification system for complete edentulism. The American College of Prosthodontics. J Prosthodont. 1999;8:27-39.

14. Allen PF, McMillan AS, Locker D. An assessment of sensitivity to change of the oral health impact profile in a clinical trial. Community Dent Oral Epidemiol. 2001;29:175-182.

15. Masood M, Masood Y, Saub R, Newton JT. Need of minimal important difference for oral health-related quality of life measures. J Public Health Dent. 2014;74:13-20.

16. Allen PF, McMillan AS, Walshaw D. A patient-based assessment of implant-stabilized and conventional complete dentures. J Prosthet Dent. 2001;85:141-147.

17. Fromentin O, Boy-Lefevre ML. Quality of prosthetic care: patient's level of expectation, attitude and satisfaction. Eur J Prosthodont Restor Dent. 2001;9:123-129.

18. John MT, Slade GD, Szentp_etery A, Setz JM. Oral healthrelated quality of life in patients treated with fixed, removable, and complete dentures 1 month and 6 to 12 months after treatment. Int J Prosthodont. 2004;17:503-511. 
19. Forgie AH, Scott BJ, Davis DM. A study to compare the oral health impact profile and satisfaction before and after having replacement complete dentures in England and Scotland. Gerodontology. 2005;22:137-142.

20. Adam RZ, Geerts GA, Lalloo R. The impact of new complete dentures on oral healthrelated quality of life. SADJ. 2007;62:264-266, 268.

21. Ellis JS, Pelekis ND, Thomason JM. Conventional rehabilitation of edentulous patients: the impact on oral health related quality of life and patient satisfaction. J Prosthodont. 2007;16:37-42.

22. Shigli K, Hebbal M. Assessment of changes in oral healthrelated quality of life among patients with complete denture before and 1 month post-insertion using Geriatric Oral Health Assessment Index. Gerodontology. 2010;27: 167-173.

23. Jabbour Z, Emami E, de Grandmont P, Rompr_e Feine JS. Is oral-health related quality of life stable upon rehabilitation with mandibular two implant dentures? Clin Oral Implants Res. 2011;23:1205-1209.

24. Viola AP, Takamiya AS, Monteiro DR, Barbosa DB. Oral health-related quality of life and satisfaction before and after treatment with complete dentures in a dental school in Brazil. J Prosthodont Res. 2013;57:36-41.

25. Aarabi G, John MT, Schierz O, Heydecke G, Reissmann DR. The course of prosthodontic patients' oral health-related quality of life over a period of 2 years. J Dent. 2015;43:261- 268. 26. Gjengedal H, Berg E, Grønningsaeter AG, Dahl L, Malde MK, Bøe OE et al. The influence of relining or implant retaining existing mandibular dentures on health-related quality of life: a 2-year randomized study of dissatisfied edentulous patients. Int $\mathrm{J}$ Prosthodont. 2013;26:68-78.

27. Awad MA, Shapiro SH, Lund JP, Feine JS. Determinants of patients' treatment preferences in a clinical trial. Community Dent Oral Epidemiol. 2000;28:119-125. 